\title{
Case Report: Sarcoidosis in the lymph nodes of a breast
}

\section{cancer patient [version 1; peer review: 2 approved]}

\author{
Perwasha Kerio1, Zain Abid (D1, Masooma Abid², Desaar Zehra1, Ghulam Haider¹ \\ ${ }^{1}$ Department of Clinical Oncology, Jinnah Postgraduate Medical Centre, Karachi, Sindh, Pakistan \\ 2 Jinnah Medical \& Dental College, Karachi, Sindh, Pakistan
}

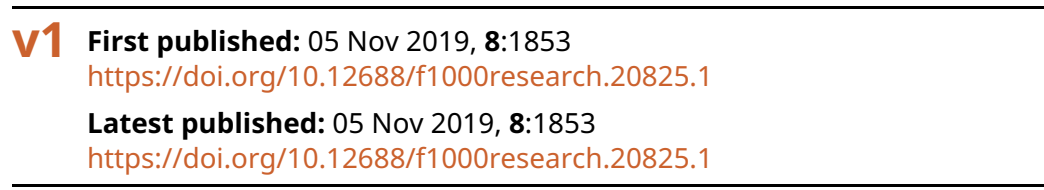

\section{Abstract}

Background: Sarcoidosis is an inflammatory disease that affects multiple organs in the body, especially the lungs and lymph nodes. The coexistence of sarcoidosis and breast cancer has been reported, but the coexistence of both diseases in the same patient often leads to misdiagnosis.

Case: We report a case of a 36-year-old woman who presented with concerns of a lump in her left breast along with pain and discharge from the nipple. On examination a 3-cm hard and tender mass was noted in the upper medial quadrant of the left breast with no palpable axillary lymph nodes.

The patient was diagnosed with an infiltrating ductal cell carcinoma of the left breast with T2N0M1 Stage IV disease, due to positive mediastinal lymphadenopathy on positron emission tomography scan. The biopsy of mediastinal lymph nodes allowed us to diagnose sarcoidosis and correctly stage her disease as T2NOMO Stage IIA breast cancer. The patient underwent lumpectomy followed by adjuvant chemo radiotherapy and hormonal therapy - corticosteroids given for sarcoidosis up to 1 year. The patient is doing well 18 months later without recurrence of disease.

Conclusion: The simultaneous occurrence of both diseases in the same patient is the risk for misdiagnosis and mismanagement, therefore it is of utmost importance to correctly stage the disease with appropriate investigations and histologic confirmation prior to initiate the treatment for breast cancer.

\section{Keywords}

breast cancer, sarcoidosis, mediastinal lymph adenopathy, positron emission tomography

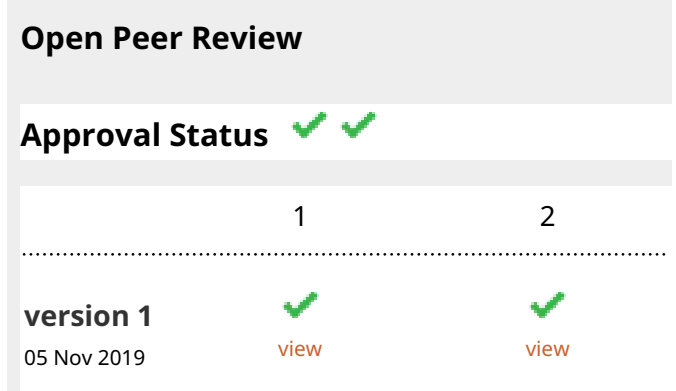

1. Jun Jiang, Chinese Academy of Medical Sciences \& Peking Union Medical College, Beijing, China

2. Tim L Jansen, Viecuri Medical Centre, Venlo, The Netherlands Any reports and responses or comments on the article can be found at the end of the article. 
Corresponding author: Zain Abid (dr.zainabid@gmail.com)

Author roles: Kerio P: Writing - Original Draft Preparation; Abid Z: Writing - Review \& Editing; Abid M: Writing - Review \& Editing; Zehra D: Writing - Review \& Editing; Haider G: Writing - Review \& Editing

Competing interests: No competing interests were disclosed.

Grant information: The author(s) declared that no grants were involved in supporting this work.

Copyright: () 2019 Kerio P et al. This is an open access article distributed under the terms of the Creative Commons Attribution License, which permits unrestricted use, distribution, and reproduction in any medium, provided the original work is properly cited.

How to cite this article: Kerio $P, A b i d Z, A b i d M$ et al. Case Report: Sarcoidosis in the lymph nodes of a breast cancer patient [version 1; peer review: 2 approved] F1000Research 2019, 8:1853 https://doi.org/10.12688/f1000research.20825.1

First published: 05 Nov 2019, 8:1853 https://doi.org/10.12688/f1000research.20825.1 


\section{Introduction}

Breast cancer is the most common cancer in women ${ }^{1}$. It is a highly curable cancer, and with proper treatment protocols, the five-year survival of Stage IV disease is $22 \%{ }^{2}$. The overall survival of a breast cancer patient depends on the stage of disease with visceral or bony metastasis; therefore at the time of initial treatment planning, it is highly important to determine the intent, which is either curative or palliative. The oncological team exerts the utmost effort to properly stage cancer by giving attention to history and clinical examination for judicious use of staging workup. Usually, on examination of breast cancer patients, the axillary lymph nodes are palpable, but internal mammary lymph node involvement is less commonly seen. We present herein a rare case of breast carcinoma with sarcoidosis. Sarcoidosis is a multisystem disease that has different grades. Most patients remain asymptomatic, and very few require treatment. It is very important to differentiate and diagnose breast cancer with metastasis or breast cancer with sarcoidosis, as there is limited literature available on the coexistence of breast cancer with sarcoidosis.

\section{Case presentation}

A 36-year-old woman presented with concerns of a lump in her left breast along with pain and discharge from the nipple. Her age of menarche was 12 years. She had no family history of breast or ovarian cancer.

We noted a $3-\mathrm{cm}$ hard and tender mass in the upper medial quadrant of the left breast. There were no palpable axillary lymph nodes. The breast ultrasound showed a solid lesion with illdefined margins in the upper medial quadrant of the left breast. The bilateral mammography demonstrated left Breast Imaging Reporting and Data System (BI-RADS) category IV and right breast BI-RADS category I.

The ultrasound-guided Tru-Cut ${ }^{\circledR}$ biopsy of the mass in the left breast showed Grade 2 infiltrating ductal cell carcinoma. The preoperative chest $\mathrm{x}$-ray showed bilateral hilar lymphadenopathy. The preoperative chest computed tomography (CT) scan showed a small $(2.5 \mathrm{~cm} \times 1.6 \mathrm{~cm})$ soft tissue density mass with speculated margins in the upper quadrant of the left breast with possible focal infiltration of the underlying chest wall muscle (Figure 1).

The results of the axillary lymphadenopathy were negative bilaterally. Multiple enlarged discrete and confluent lymph nodes were seen in the mediastinum and both hilar regions, which could have been malignant.

Positron emission tomography (PET) scan showed multiple enlarged hypermetabolic lymph nodes in the mediastinum, right paratracheal, carinal, bilateral hilar region, and aortopulmonary window (Figure 1).

The largest lymph node in the subcranial region was $1.5 \mathrm{~cm} \times$ $4.0 \mathrm{~cm}$ with a maximum standardized uptake value (SUV max) of 8.3 (Figure 2). One of the lymph nodes in the right paratracheal region measured $2.5 \mathrm{~cm} \times 2.1 \mathrm{~cm}$ with an SUV max of 9.9 , likely representing metastasis.

The bronchoscopic biopsy of mediastinal lymph node showed non-caseous necrotic granulomatous inflammation, suggestive of sarcoidosis. This allowed us to correctly stage the disease as T2N0M0 stage IIA. The patient underwent lumpectomy followed by adjuvant chemotherapy, radiotherapy and hormonal

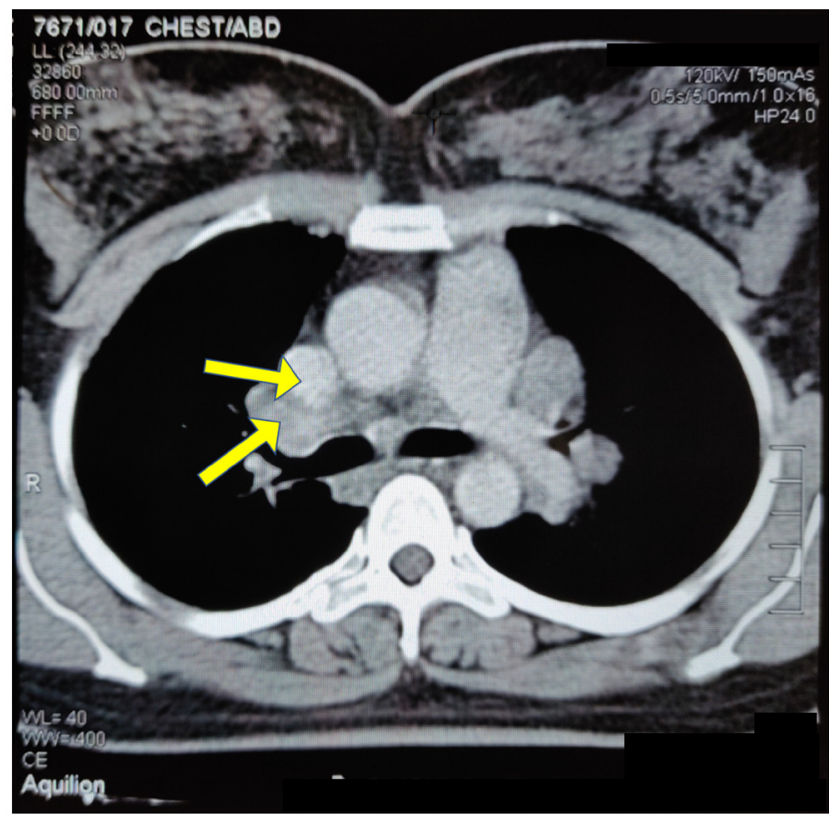

Figure 1. Preoperative chest computed tomography scan. Small $(2.5 \mathrm{~cm} \times 1.6 \mathrm{~cm})$ soft tissue density mass with speculated margins in the upper quadrant of the left breast with possible focal infiltration of the underlying chest wall muscle is observed (shown by yellow arrows).

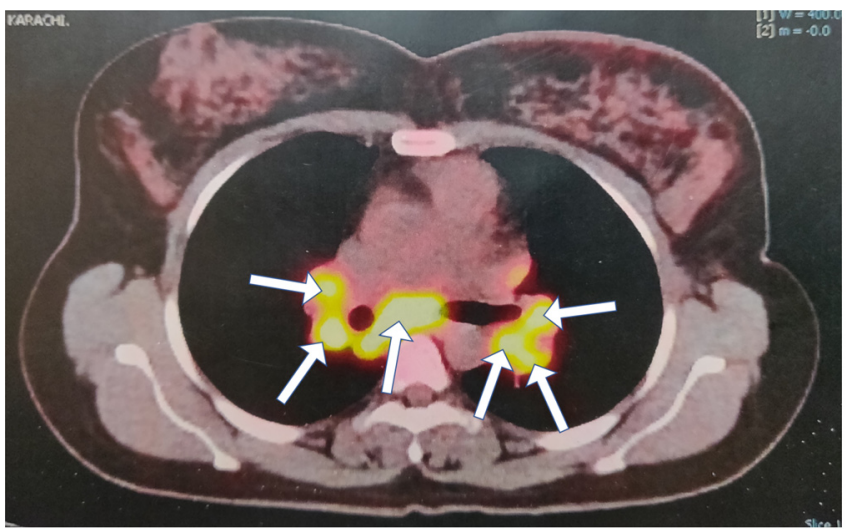

Figure 2. Positron emission tomography scan. Multiple enlarged hypermetabolic lymph nodes in the mediastinum, right paratracheal, carinal, bilateral hilar region, and aortopulmonary window are observed (shown by yellow arrows). 
therapy for breast cancer, while corticosteroids (prednisone, $1 \mathrm{mg} / \mathrm{kg}$ for 9 months then tapered off over period of 3 months) were given for sarcoidosis for 1 year. The patient is being followed up with clinical examination every 3 months and breast mammogram done initially at 6 months following completion of radiotherapy (post mastectomy radiation therapy, total dose of 60 Gy: $50 \mathrm{~Gy}$ in 25 fractions given to chest wall with scar boost $10 \mathrm{~Gy}$ in 5 fractions) then at 1 year. At 18 months, there is no evidence of recurrence of disease and the patient is well.

\section{Discussion}

Sarcoidosis is a multisystem granulomatous disease of unknown aetiology that manifests as non-caseating granulomas predominantly in the lungs, intrathoracic lymph nodes, and skin. The less commonly affected organs are the eyes, liver, heart, and brain. Sarcoidosis is more common in women; it occurs in patients aged 20 to 50 years $^{3}$. The incidence rate is higher among African Americans. Many features of sarcoidosis are suggestive of infectious origin ${ }^{4}$. The diagnosis of sarcoidosis requires radiographic signs (e.g., bilateral hilar lymphadenopathy and pulmonary infiltrations $)^{3}$ and non-caseating granulomas on histopathology. Chronic inflammation is associated with an increased risk for malignant lymphoma and cancer in the affected tissue. The association between sarcoidosis and cancer is indistinct; although it has been proposed that patients with sarcoidosis are at increased risk for developing cancer of the lung, small intestine, stomach, liver, and skin ${ }^{4}$. Cancer can produce sarcoid-like reactions in the lymph nodes, and sarcoidosis can occur in patients with cancer. The radiological features of neoplasms can be mistaken for sarcoidosis. Therefore, histologic confirmation is required before making a diagnosis ${ }^{3,5}$.

There is increased risk of breast cancer occurrence in patients with sarcoidosis than other inflammatory diseases ${ }^{5}$. Lungs are common sites for breast cancer metastasis and are detected on chest radiographs in $25 \%$ of patients ${ }^{4,5}$.
Cavitation of metastatic nodule is a rare feature on radiography. However, cavitation in metastatic adenocarcinoma including breast cancer is frequently seen on $\mathrm{CT}^{5}$. The axillary, mediastinal, and hilar lymph nodes are commonly involved. PET/CT imaging is superior in detecting distant metastasis in patients with stage II and stage III breast cancer, but false positive 18F-fluorodeoxyglucose (FDG) uptake and negative PET/CT are frequently seen $^{6}$. The conditions that cause false positive FDG uptake for malignancy include tuberculosis, fungal infection, and sarcoidosis. Initial staging with PET/CT is not recommended in preoperative early stage breast cancer because of high suboptimal sensitivity of the axillary lymph nodes, but specificity is high, and it has excellent positive predictive value confirming immediate axillary dissection instead of sentinel lymph node biopsy in the presence of high FDG uptake. However, sentinel lymph node biopsy is necessary if there is normal or slightly increased FDG uptake ${ }^{6}$.

Sarcoidosis has been reported to increase levels of CA 15-3 in some cases, so the presence of this biomarker might be misleading ${ }^{7}$.

\section{Conclusions}

If abnormal FDG uptake is detected on FDG PET in isolated mediastinal lymph nodes, in the absence of axillary lymph node involvement in patients with breast cancer, a thorough preoperative evaluation is warranted with histopathologic confirmation, thereby allowing the choice of correct staging and curative strategy.

\section{Consent}

Written informed consent was obtained from the patient for the publication of this case report and any associated images.

\section{Data availability}

All data underlying the results are available as part of the article and no additional source data are required.
1. Bray F, Ferlay J, Soerjomataram I, et al.: Global cancer statistics 2018: GLOBOCAN estimates of incidence and mortality worldwide for 36 cancers in 185 countries. CA Cancer J Clin. 2018; 68(6): 394-424. PubMed Abstract | Publisher Full Text

2. Howlader N, Noone AM, Krapcho M, et al:: SEER Cancer Statistics Review, 1975-2014. Bethesda: National. Cancer, Institute; 2017; Reference Source

3. Koo HJ, Kim MY, Shin SY, et al.: Evaluation of Mediastinal Lymph Nodes in Sarcoidosis, Sarcoid Reaction, and Malignant Lymph Nodes Using CT and FDG-PET/CT. Medicine (Baltimore). 2015; 94(27): e1095. PubMed Abstract | Publisher Full Text | Free Full Text

4. Dragoumis DM, Tsiftsoglou AP, Assimaki AS: Pulmonary sarcoidosis simulating metastatic breast cancer. J Cancer Res Ther. 2008; 4(3):
134-6.

PubMed Abstract | Publisher Full Text

5. Kochoyan T, Akhmedov M, Shabanov A, et al:: Sarcoidosis imitating breast cancer metastasis: a case report and literature review. Cancer Biol Med. 2016 13(3): 396-398.

PubMed Abstract | Publisher Full Text | Free Full Text

6. Altınkaya M, Altınkaya N, Hazar B: Sarcoidosis mimicking metastatic breast cancer in a patient with early-stage breast cancer. Ulus Cerrahi Derg. 2015; 32(1): 71-4.

PubMed Abstract | Publisher Full Text | Free Full Text

7. Chen J, Carter R 3rd, Maoz D, et al.: Breast Cancer and Sarcoidosis: Case Series and Review of the Literature. Breast Care (Basel). 2015; 10(2): 137-40. PubMed Abstract | Publisher Full Text | Free Full Text 


\section{Open Peer Review}

\section{Current Peer Review Status:}

\section{Version 1}

Reviewer Report 16 March 2021

https://doi.org/10.5256/f1000research.22905.r80201

(C) 2021 Jansen T. This is an open access peer review report distributed under the terms of the Creative Commons Attribution License, which permits unrestricted use, distribution, and reproduction in any medium, provided the original work is properly cited.

\section{Tim L Jansen}

Department of Rheumatology, Expert Centre for Complex Gout, Viecuri Medical Centre, Venlo, The Netherlands

I agree on the interest for your readership on this case report. Interesting case report on the simultaneous occurrence of breastca and granulomatous disease so called sarcoidosis.

Diagnostic issues are elegantly depicted.

I think the paper is ready for indexing with a minor improvement on:

Therapeutic considerations regarding the finding of granulomatous tissue in biopsy versus malignant cells in biopsy only.

Pharmacotherapeutic options.

Is the background of the case's history and progression described in sufficient detail? Yes

Are enough details provided of any physical examination and diagnostic tests, treatment given and outcomes?

Yes

Is sufficient discussion included of the importance of the findings and their relevance to future understanding of disease processes, diagnosis or treatment? Partly

Is the case presented with sufficient detail to be useful for other practitioners? Yes

Competing Interests: No competing interests were disclosed. 
I confirm that I have read this submission and believe that I have an appropriate level of expertise to confirm that it is of an acceptable scientific standard.

Reviewer Report 12 June 2020

https://doi.org/10.5256/f1000research.22905.r56717

(C) 2020 Jiang J. This is an open access peer review report distributed under the terms of the Creative Commons Attribution License, which permits unrestricted use, distribution, and reproduction in any medium, provided the original work is properly cited.

Jun Jiang

National Cancer Center/National Clinical Research Center for Cancer/Cancer Hospital, Chinese Academy of Medical Sciences \& Peking Union Medical College, Beijing, China

1. CT is not the first choice for breast cancer . It should provide ultrasound, X-ray and MRI imaging data.

2. Breast cancer patients without axillary lymph node metastasis, but found a large number of mediastinal swollen lymph nodes, such cases are very rare.First of all, we need to analyze the relationship between breast tumor and mediastinal enlarged lymph node. If two different diseases are considered, breast cancer is considered as breast cancer, while mediastinal enlarged lymph nodes can be metastatic lymph nodes, sarcoidosis or lymphoma.If breast and mediastinum are considered as the same disease, lymphoma should be considered first.

3. The case report has not been discussed in detail in terms of examination method, diagnosis and differential diagnosis, and has limited value in clinical guidance.

Is the background of the case's history and progression described in sufficient detail? Yes

Are enough details provided of any physical examination and diagnostic tests, treatment given and outcomes?

Partly

Is sufficient discussion included of the importance of the findings and their relevance to future understanding of disease processes, diagnosis or treatment?

Partly

Is the case presented with sufficient detail to be useful for other practitioners? Partly

Competing Interests: No competing interests were disclosed. 
Reviewer Expertise: Diagnosis of tumor imaging

I confirm that I have read this submission and believe that I have an appropriate level of expertise to confirm that it is of an acceptable scientific standard.

The benefits of publishing with F1000Research:

- Your article is published within days, with no editorial bias

- You can publish traditional articles, null/negative results, case reports, data notes and more

- The peer review process is transparent and collaborative

- Your article is indexed in PubMed after passing peer review

- Dedicated customer support at every stage

For pre-submission enquiries, contact research@f1000.com 